\title{
COSMOLOGIAS E ONTOLOGIAS AMERÍNDIAS NO SUL DO BRASIL: ALGUMAS REFLEXÕES SOBRE O PAPEL DOS CIENTISTAS SOCIAIS FACE AO ESTADO
}

SERGIO BAPTISTA DA SILVA ${ }^{1}$

UFRGS

Palestra conferida no âmbito do Seminário Internacional "Ciencias sociales y estudios culturales", realizada na Universidad Nacional del Altiplano, Puno-Peru, promovido pela Faculdad de Ciencias Sociales e Escuela Profesional de Sociologia, em 22 de setembro de 2010, com a participação de docentes e alunos.

Com meus sinceros agradecimentos pelo convite em participar desse Seminário, vou começar mostrando esses mapas que estão aí na tela, para precisar a região do Brasil sobre a qual estarei me referindo. Trata-se do sul do Brasil, do estado do Rio Grande do Sul. De momento, eu vou me focar nos coletivos indígenas desta parte meridional do Brasil, em suas cosmologias e ontologias. Nas outras exposições, falarei sobre esta área indicada no mapa, sobre a territorialidade guarani e

\footnotetext{
${ }^{1}$ Doutor em Antropologia Social pela USP, Professor no Departamento de Antropologia e no Programa de Pós-graduação em Antropologia Social da Universidade Federal do Rio Grande do Sul. E-mail: sergiobs@terra.com.br.
} 
particularmente sobre os grupos técnicos de identificação e caracterização de terras indígenas no meu país.

O que são cosmologias? Cosmologias são formas teóricas que cada povo, que cada etnia, que cada coletivo tem sobre o mundo, sobre o cosmos. As suas percepções culturais, filosóficas, sociológicas, políticas, das suas relações entre si. É sobre cosmologias ameríndias de coletivos indígenas do sul do Brasil, especialmente os Guarani e os Kaingang que gostaria de apresentar para vocês e fazer algumas reflexões sobre elas. Certamente pretendo, não durante esta exposição, neste primeiro momento, porém nos próximos dias, tentar fazer algumas relações com as populações tradicionais aqui do Peru, com quem eu tive um encontro muito recente, pois estou aqui há menos de dez dias.

Neste sentido, a intenção, o objetivo geral destas exposições é a de poder proporcionar para vocês alunos, estudantes, essas possibilidades teórico-metodológicas de podermos entender essas populações nativas, tradicionais, a partir da compreensão, das suas cosmologias, das suas teorias sobre o mundo, das suas percepções, das suas visões, das suas cosmovisões sobre o mundo.

Ao lado de cosmologia, outro conceito importante para essa minha exposição é o de ontologia. O que é uma ontologia? Toda a forma particular, singular, de cada etnia, de cada povo, de cada coletivo, a respeito da sua forma de ser, de ser e de estar no mundo constitui-se em uma ontologia. Como cada uma dessas populações se veem enquanto seres neste mundo.

Então, estes dois conceitos serão importantes para que nós, a partir deles, possamos pensar esses coletivos ameríndios do Brasil meridional.

No "ocidente", desde a Europa, desde os países que foram colonizados - para dizer a palavra certa, foram "conquistados" pelos povos europeus -, existe toda uma forma de visão cosmológica que difere muito das cosmologias e das ontologias dos povos originários da América Latina. Estas concepções do cosmos e do ser, elas estão relacionadas com as intrincadas, imbricadas e não separadas formas de relação entre o homem e a natureza. No Ocidente, na Europa, e em todas as regiões onde imperam concepções eurocentradas, que têm 
como referências as lógicas europeias, existe uma separação entre natureza e cultura; existe uma separação muito forte entre natureza e sociedade. Por exemplo, as concepções e as lógicas europeias de cosmologia, de teoria sobre o mundo, elas concebem o homem fora da natureza. Este homem europeu, ou com lógicas eurocêntricas, se pensa plenamente afastado da natureza; vê os animais, as plantas, os seres metereológicos, do céu, inanimados, como se fossem seres outros, completamente, ontologicamente, separados da humanidade, da cultura. Então existe, nessa lógica eurocêntrica, designada de naturalismo por Philippe Descola, uma separação ontológica e cosmológica entre os humanos e os demais outros seres, os outros existentes. Como a drástica e irremediável separação entre humanidade e animalidade, por exemplo.

Entretanto, de acordo com muitos estudos etnográficos e teóricos de antropólogos, sociólogos e cientistas sociais, esta não é a única possibilidade de uma teoria sobre o mundo, de uma teoria a respeito do cosmos.

A primeira constatação destes estudos é que outros povos, outros coletivos, em outros lugares do mundo, não fazem a separação entre natureza e cultura, não estabelecendo uma distinção entre estes domínios do cosmos, que são percebidos como intercambiáveis, interdependentes e com fronteiras porosas. A segunda, conforme Bruno Latour, seria a de que no "ocidente", apesar de ser caracterizado pela oposição entre natureza e cultura, ela é muito recente, ideológica, e pretende escamotear as relações natureza-cultura existentes mesmo na "modernidade".

Retornando à primeira constatação, estes povos, principalmente os coletivos das terras baixas da América Latina, concebem que os animais tenham atributos que são atributos humanos: subjetividade, cultura e ponto de vista. Em outras palavras, para estas cosmologias, não existe uma separação entre homens, plantas, animais e seres "inaminados". Para esses coletivos, para essas etnias, nas suas cosmologias, existe uma integração, uma imbricação entre os domínios animal, vegetal, humano, metereológico, das divindades etc., como se todos eles estivessem fazendo parte de um único cosmos, todos seus elementos sendo concebidos como pessoas, existentes, com os quais é 
SERGIO BAPTISTA DA SILVA - Cosmologias e ontologias ameríndias no sul do Brasil...

possível estabelecer relações socais. Nelas, há gradações, mas não separações. Entre estes existentes, humanos ou extra-humanos animais, plantas, divindades, astros, "coisas" - há gradações hierárquicas. Então o homem seria, para essas formas lógicas de se pensar, cosmológicas de se pensar, ele estaria num grau mais alto de humanidade. Mas um animal, por exemplo um puma, ele também teria subjetividade, humanidade, cultura, alma e ponto de vista, com ele sendo possível a comunicação e a relação social. Deste modo, essa forma de se pensar é especialmente diferente das formas europeias, eurocêntricas, de se pensar, e elas são o que os antropólogos chamam de ontologias animistas ou perspectivistas. Animistas porque cada um desses outros seres, considerados pessoas, são extra-humanos, ou existentes, e que eles teriam espírito, alma, vontade, subjetividade, emoções, e seriam assim considerados por esses povos das terras baixas da América do Sul.

Como disse-lhes no início, quero discorrer, nesta palestra, particularmente sobre dois coletivos ameríndios do sul do Brasil: os Guarani e os Kaingang.

Começo com os Guarani. Há uma integração muito grande, muito forte, entre os seres que existem na "natureza", como nós diríamos, nos territórios, nas terras desse coletivo - e a pessoa guarani. Então, só para começar com alguns exemplos, eu mostro aqui a imagem de uma taquara. É um vegetal extremamente importante; com ele, eles confeccionam, por exemplo, instrumentos musicais e cestas. Então, é uma planta de grande importância econômica e concreta nas suas vidas. Mas o que me interessa particularmente aqui, para além dessa forma instrumental do uso dos recursos naturais na floresta, por detrás dessa relação operacional que os índios Guarani têm com a taquara - e essa é a noção que eu quero trabalhar com vocês agora -, é a existência de uma outra lógica, que impõe uma série de cuidados rituais no estabelecimento de suas relações com a taquara. Em outras palavras, ao estabelecer esta relação, ela é considerada como social, pois este vegetal é concebido como pessoa, nas gradações hierárquicas antes comentadas, o que faz com que os Guarani precisem pedir permissão para o "dono" da taquara, que é o "senhor e protetor" da taquara, seu já, para que exista a possibilidade de cortá-la e utilizá-la para fazer balaios 
ou instrumentos musicais.

Cada coletivo de seres vegetais, animais ou minerais tem um senhor, um dono, que é uma entidade, uma deidade, uma divindade, que possui sobre ele uma série de relações de proteção. Assim, estamos falando de uma cosmologia que integra e articula os seus vários domínios, concebendo-os como imbricados e interdependentes. Desta forma, toda vez que um Guarani fizer uso daquilo que no "ocidente" diríamos "natureza", usar um "recurso da natureza", seja a taquara, seja a caça de um animal, seja o uso das águas, ele precisa pedir permissão ao seu já, seu "ser protetor", uma atitude de respeito ao senhor da água, ao senhor desses "recursos naturais", para que eles possam ser utilizados. E, certamente, estas relações envolvem uma ontologia do ser guarani na qual está presente uma concepção multinaturalista dos existentes do cosmos: todos os seres possuindo interioridades semelhantes (cultura, subjetividade, humanidade) com exterioridades (corpos, naturezas) diferentes. Trata-se, então, de uma concepção cosmológica e ontológica na qual não existe separação entre os domínios e na qual os seres, os existentes, são pensados como sujeitos plenos, com agência uns sobre os outros. Cada um desses seres, eles têm vontade e eles têm também um ponto de vista; ou seja, um animal, segundo essas formas lógicas e cosmológicas, um animal ele tem um ponto de vista e pode enxergar o homem como sendo um animal, por exemplo. Um puma, uma ave, ele pode ver o homem enquanto sua caça, porque ele tem um ponto de vista, ele tem uma perspectiva, que é uma perspectiva humana e que pode enxergar esse outro ser humano como sendo um ser animal e vegetal, ele próprio concebendo-se como humano.

Bom, certamente, esta lógica amplia os agentes do mundo, conforme discutia inovadoramente Gabriel Tarde, na França, no final do século XIX, numa tradição perdida das Ciências Sociais e só recentemente retomada e valorizada. Não só humanos compõem as redes de relações possíveis. Os extra-humanos, e as relações que com eles os Guarani estabelecem, e vice-versa, multiplicam consideravelmente os agentes, os existentes do cosmos, influenciando diretamente nas concepções êmicas sobre pessoa e corpo.

Assim, é importante também pensar que essa taquara não vai ser 
usada apenas para se fazer um cesto, para se fazer um instrumento musical. Ela vai ser utilizada para confeccionar um colar, para se colocar ao redor do pescoço, junto ao corpo, e esse colar, que desde a lógica "eurocêntrica" vai ser considerado um objeto de adorno, será um importante elo de transmissão de todas as propriedades imateriais que essa taquara tem para dentro do corpo dessa pessoa guarani que usar o colar. São formas de incorporação dessas essências, desses espíritos, dessas propriedades imateriais que estão nas alteridades extrahumanas e que podem ser trazidos para dentro dos corpos dessas pessoas, contribuindo para a construção e proteção de seus corpos. $\mathrm{Na}$ verdade, estes "adornos" são presentificações destes encontros com as alteridades extra-humanas e que têm agência sobre os corpos humanos, os quais devem ser considerados como "corpos compósitos", conforme Cecília MacCallun, uma vez que são compostos por inúmeras incorporações de propriedades imateriais, essências, presentes nestes seres extra-humanos com os quais são estabelecidos relações sociais.

Eu gostaria de dar mais alguns exemplos e comentá-los. Tanto entre os Guarani como entre os Kaingang, esses ditos "recursos naturais", eles não ficam apenas ao nível do utilitário. Estou mostrando para vocês aí na tela uma planta popularmente chamada de urtiga. Para os coletivos indígenas citados, ela tem várias utilidades, desde fabricar tecidos com suas fibras até para retirar do corpo algumas dores. Podemos pensar esse uso como muito utilitário, pragmático, muito funcional. Entretanto, focando a segunda utilização comentada, para além deste uso enquanto plantas medicinais (que vão contribuir para essa rica experiência, para essa rica sabedoria tradicional de um conhecimento sobre os usos, sobre os usos para curar males, curar dores), co-existem também esses usos de incorporação desses elementos imateriais presentes nessa planta, realizados de variados modos: chás, banhos ou "adornos" trazidos junto ao corpo. Então, para além da cura e de todo esse conhecimento e sabedorias tradicionais sobre essa planta, existem também essas relações de incorporação dessas essências desses seres da mata, que são incorporadas nesses corpos para que a pessoa se torne humana e que se componha de várias outras alteridades extra-humanas ou partes. E essas partes vêm exatamente dessas formas que nós, do "ocidente", com as lógicas 
eurocêntricas, chamamos de natureza - porque eles não fazem essa distinção entre o que é natureza e o que é cultura, o que é humanidade.

Continuando com a exemplificação, existe uma ave no sul do Brasil chamada saracura. Ela tem pernas longas e uma capacidade de correr, de se mobilizar, muito grande. É exatamente essa mobilidade e esse estar ereto sobre pernas fortes que são um conjunto de atributos fortemente requeridos pelos coletivos guarani. Por quê? Porque a população guarani, eles se deslocam muito por seu amplo e transnacional território. Vocês lembram daquele mapa anterior que eu tinha mostrado pra vocês, do sul do Brasil? Então, existem aldeias e acampamentos guarani em pelo menos os seis estados mais ao sul do Brasil - que é RS, SC, PR, SP, RJ e ES, além de estarem presentes no Paraguai, Argentina e parte do Uruguai, o que configura um amplo território guarani -, no qual eles têm uma mobilidade, eles estão sempre indo de locais a locais e não reconhecem essas fronteiras nacionais. Tem uma grande semelhança com a própria cultura andina, onde existe toda integração, que vai para além das fronteiras nacionais entre Peru, Bolívia e Argentina. Então, nesse território amplo que abrange o sul do Brasil e porções do Paraguai, da Argentina e do Uruguai, esses coletivos guarani exercem uma grande mobilidade. Retornando ao exemplo da ave, a saracura, eles fazem colares e pulseiras com os ossos das pernas da saracura, os quais são usados pelas crianças, para que elas adquiram todas essas propriedades imaterias, para que elas incorporem todas essas essências presentes na interioridade das saracuras e que seus pais querem que sejam transmitidas aos corpos e às pessoas de seus filhos.

Então, para além de crenças ou misticismos, para além de marcar etnocentricamente que estas lógicas são formas supersticiosas ou "primitivas" de se pensar, é necessário ser afetado por essas lógicas e categorias nativas. Precisamos, enquanto cientistas sociais, e essa é a minha postura enquanto antropólogo, respeitar, sermos afetados por esses conceitos nativos, por essas filosofias que esses povos estão nos colocando, numa atitude simétrica. Por quê? Porque é a partir da compreensão dessas cosmologias e ontologias é que podemos, enquanto cientistas sociais, informar políticas públicas ou governamentais, influenciando o estabelecimento de relações 
simetrizantes entre estes coletivos e o Estado. E é essa a relação que nós, cientistas sociais, precisamos fazer, a partir da compreensão dessas lógicas e a partir de todas as formas de políticas públicas e de ações governamentais que vão incidir sobre esses coletivos. Imaginem vocês os grandes problemas que podem surgir na aplicação de políticas de saúde pública para o povo guarani ou kaingang se os gestores destas políticas, se os agentes políticos governamentais, não compreenderem e não se darem conta de que essa lógica é a lógica desses grupos. O que acontece com as políticas públicas que não dão conta dessas lógicas singulares e particulares? Elas vão impor uma série de formas de atenção à saúde, que são muito mais lógicas eurocêntricas, "ocidentais", biomédicas, que não vão se dar conta das particularidades dessas lógicas. Então, é exatamente a partir desse ponto que eu quero começar a fazer com vocês, agora, um exercício sociológico de refletir sobre a utilização prática dessa compreensão cosmológica e ontológica com relação às atenções para saúde, para atenção à moradia e para uma série de outras políticas que precisam então ser planejadas, dirigidas e executadas de uma forma a compreender, respeitar, ser afetado e dar valor à diversidade cultural e à diversidade sociológica, a partir das singularidades cosmológicas e ontológicas desses coletivos.

Assim, é exatamente esta relação que eu gostaria de fazer com vocês - e já também já refletindo um pouco sobre os aspectos das outras palestras propostas para a sequência do Simpósio -: de falar sobre o papel fundamental das ciências sociais, do papel fundamental dos cientistas sociais, dos antropólogos, dos cientistas políticas e dos sociológicos em propor projetos que objetivem a compreensão dessas particularidades, que sejam afetados por esses conceitos e que possam pensar e encarar essas lógicas não como formas místicas, ilógicas ou crenças. Mas exatamente a importância dos cientistas sociais de poder articular diplomaticamente, no sentido de Bruno Latour, uma aproximação verdadeira, uma escuta de qualidade desses conceitos nativos, e a partir daí informarem, discutirem e proporem políticas públicas mais próximas das lógicas nativas em um contexto simetrizante.

Com relação aos Guarani e Kaingang, sobre os quais estou falando para vocês, esses coletivos do sul do Brasil afirmam que 
precisam também de uma atenção à saúde desde o ponto de vista da biomedicina. Eles afirmam precisar de postos de saúde. Eles dizem, eles requerem, eles reivindicam isso. Eles querem médicos, enfermeiros; eles querem odontólogos e toda sorte de pessoal ligado à medicina "ocidental". Entretanto, eles querem também o respeito das suas lógicas, suas formas de conhecimento, porque para eles existem doenças que são doenças que vêm dos não indígenas, dos "brancos" como eles chamam no Brasil as populações com ascendência europeia -, e outras doenças que são doenças ligadas a essas lógicas ameríndias. Então, o que eles querem? O respeito do ponto de vista dessas práticas xamânicas, que são todas essas práticas xamânico-cosmológicas que levem em contas este tipo de lógica particular. Mas, ao mesmo tempo, quando o xamã, quando as suas lógicas não dão conta daquelas doenças, não as curam, eles dizem: bom, essas são doenças originárias do mundo branco, do mundo "ocidental"; então nós precisamos dessas políticas públicas nesse sentido e em todas as formas de atenção à saúde, desde a gestação para as mulheres, o parto e uma série de outras formas de atenção que eles querem ser respeitados.

Um outro elemento da singularidade dessas cosmológicas, dessas ontologias, dessas formas de se perceber, como já mencionei anteriormente, é a própria forma de conceber a pessoa. No "ocidente", e existem vários autores que falam sobre isso, especialmente Louis Dumont, que é uma referência principal para entender esse processo, houve toda uma formação histórica e cultural relacionada ao processo de individualização, que Dumont designa como uma forma ideológica de concepção do ser. Então, a partir de uma série de procedimentos e de processos históricos que aconteceram na Grécia Antiga, na Europa na Idade Média, com a religião católica, existe o lento aparecimento da concepção de indivíduo, que se percebe como tal frente aos outros. Assim, resumindo grosseiramente, no "ocidente" cada um de nós é um indivíduo e, portanto, se percebe ideologicamente como um ser da sua vontade, um ser individual, que não é divisível, um ser que é único. No "ocidente", cada um se percebe como um ser único, que não pode ser dividido, por isso se diz indivíduo. Nesses coletivos ameríndios sobre os quais estou falando para vocês, do sul do Brasil, o que se estende para as terras baixas da América Latina, não existe um conceito de indivíduo, 
existe o conceito de divíduo, o ser que pode ser dividido. É uma concepção ontológica do ser que é dividido. Isso vem de muitos teóricos, Marilyn Strathern é uma referência importantíssima para essa questão. De qualquer forma, o que diz essa teórica? Que esses seres todos, que vão, por exemplo, buscar a agilidade e a mobilidade da ave saracura, ou que vão buscar a fortaleza de uma árvore, a durabilidade de uma árvore como a figueira, através de pulseiras confeccionadas com suas fibras e usadas junto aos seus corpos, eles estão incorporando uma série de atributos, de peculiaridades, de particularidades desses animais e dessas plantas nos seus corpos e estão se tornando seres que são seres compostos. Então, não existe um indivíduo nessas sociedades originárias sul-americanas; existem divíduos, serem que são compostos de vários outros seres, que recebem propriedades imateriais dessas alteridades. Nesse sentido, políticas públicas ou governamentais para esses coletivos precisam levar em conta como eles se percebem como seres que são compostos por vários outros seres. E que deveriam ser políticas, então, que dessem conta desse direito à diversidade e à singularidade cosmológica e ontológica desses coletivos.

De novo, insisto e fecho essa primeira fala mostrando como é importante o papel do cientista social na compreensão dessa diversidade cultural, sociológica, ou melhor, desses diversos mundos possíveis. E como é importante, também, que, nos nossos projetos de ciências sociais, possamos agregar outros profissionais. Então, aqui, por exemplo, estou mostrando um cesto, uma arte dos Guarani, onde tem vários grafismos que estão presentificando e representando a cobra. Assim, a partir da compreensão destas lógicas, conforme exposto antes, um aluno ou um pesquisador ligado à área da arte vai ter muito mais condições de se incorporar a um projeto desse tipo e vai estudar por que a cobra, a serpente, está presente nesta cesta. E vários outras alteridades extra-humanas, além da cobra, como outros animais, plantas e divindades, que foram presentificados e representados em cestos, em grafismos, ou outros artefatos. O que está em jogo é a constituição de grupos ou projetos multidisciplinares, onde, por exemplo, biólogos, botânicos, médicos são importantes para refletir sobre essas lógicas singulares e constituir uma compreensão mais abrangente e articulada das lógicas desses coletivos, que, como se viu, 
articulam e imbricam domínios que consideramos apartados. Deste modo, o que estou trazendo para vocês é exatamente a tentativa de uma compreensão multidisciplinar. Trazer muitos cientistas para dentro de uma discussão nas Ciências Sociais, para podermos atingir uma compreensão o mais simétrica possível dessas cosmologias, dessas ontologias, para que possamos informar políticas públicas e governamentais, que são necessárias à continuidade de mundos possíveis, à permanência da diversidade cultural e sociológica desses grupos, sem imposições que venham de fora. Então, o papel dos cientistas sociais é fundamental como coordenadores deste amplo projeto que envolve a compreensão da cosmologia e das ontologias desses coletivos. Muito obrigado. 